\title{
Diagnosis of a mucinous pancreatic cyst and resection of an intracystic nodule using a novel through-the-needle micro forceps
}

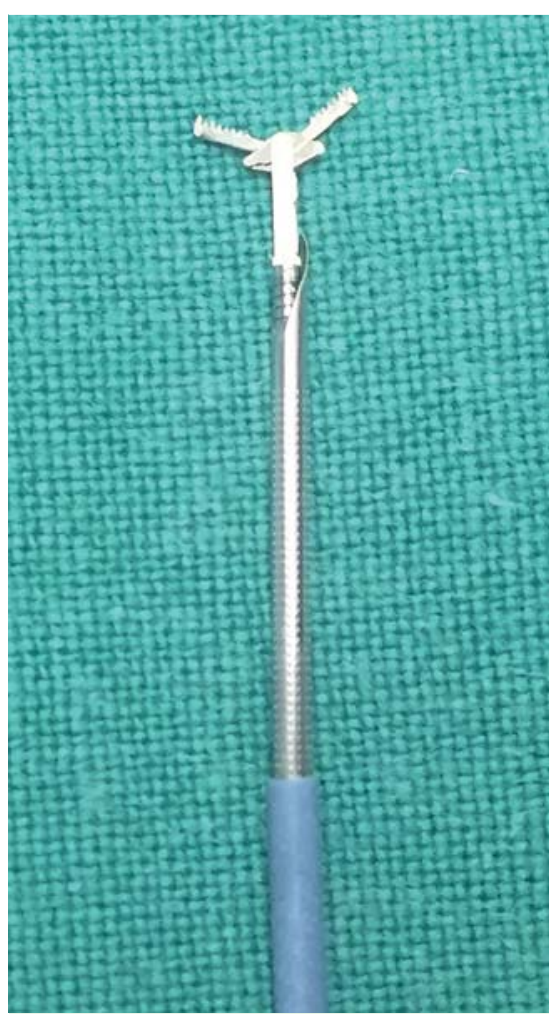

Fig. 1 Micro forceps inside a 19G fine-needle aspiration needle.

Pancreatic cystic lesions (PCLs) are detected in over $2 \%$ of patients who undergo computed tomography (CT) and magnetic resonance imaging screening [1,2]. Most PCLs are harmless, but some have the potential for malignant transformation. The management of PCLs is challenging, with high resource use. The standard option for the acquisition of cellular material from PCLs is endoscopic ultrasound (EUS)-guided fine-needle aspiration (FNA). Although many types of needles are available [3], it is usually not possible to obtain a reliable biopsy from the cyst wall for a more certain histological diagnosis. In four recently reported cases, a through-the-needle forceps was used to obtain biopsies from PCLs [4-6]. We report the first case in which a novel through-the-needle micro forceps (Moray, US Endoscopy, Ohio, USA) ( $\bullet$ Fig. $\mathbf{1}$ ) was used to diagnose a PCL, and to biopsy and resect an intracystic nodule.

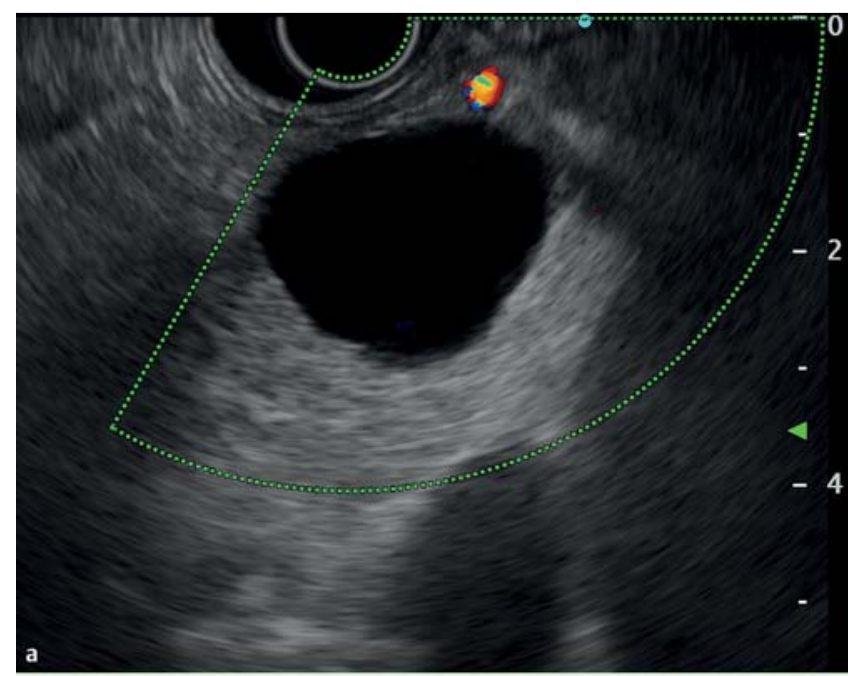

Fig. 2 Endoscopic ultrasound of pancreatic cyst with an intracystic nodule. a The pancreatic cyst. Color Doppler was used to exclude major vessels prior to puncture. b A nodule could be seen inside the cyst.

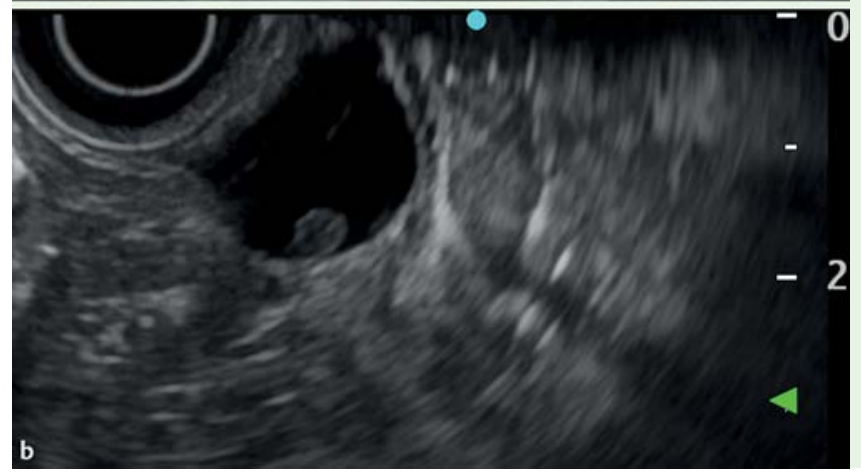

The patient was an 85-year-old woman with an incidental finding of a $30 \times 20 \mathrm{~mm}$ solitary PCL in the body of the pancreas on CT scan. The finding was also apparent on EUS. The lesion showed no connection with the pancreatic ducts, but a small nodule could be seen inside the cyst ( Fig. 2a,b). A 19-G FNA needle (EchoTip Ultra; Cook Medical, Limerick, Ireland) was used to access the cyst. After the stylet was removed, a micro forceps was advanced through the FNA needle into the cyst, and four biopsies were taken from the cyst wall. In addition, the cyst fluid, which was serous, was aspirated. The nodular lesion was biopsied and then resected $(\bullet$ Video 1$)$.

The patient was observed for 2 hours after the procedure, and then discharged. No complications were reported at 2 weeks' follow-up. The cyst fluid revealed few mucinous cells. Carcinoembryonic antigen and amylase levels were in the nor- mal range. The biopsies showed mucinous epithelium consistent with a mucinous cyst, and a nodule made up of connective tissue with a mucinous lining ( $\bullet$ Fig. 3 ).

Endoscopy_UCTN_Code_TTT_1AS_2AD

Competing interests: None

Khanh Do-Cong Pham ${ }^{1,2,3}$, Trond Engjom ${ }^{1,2,3}$, Hilde Gjelberg Kollesete $^{4}$, Lars Helgeland ${ }^{2,4}$

${ }^{1}$ Department of Medicine, Haukeland University Hospital, Bergen, Norway 2 Department of Clinical Medicine, K1, University of Bergen, Bergen, Norway

${ }^{3}$ National Centre for Ultrasound in Gastroenterology, Haukeland University Hospital, Bergen, Norway University Hospital, Bergen, Norway
${ }^{4}$ Department of Pathology, Haukeland 


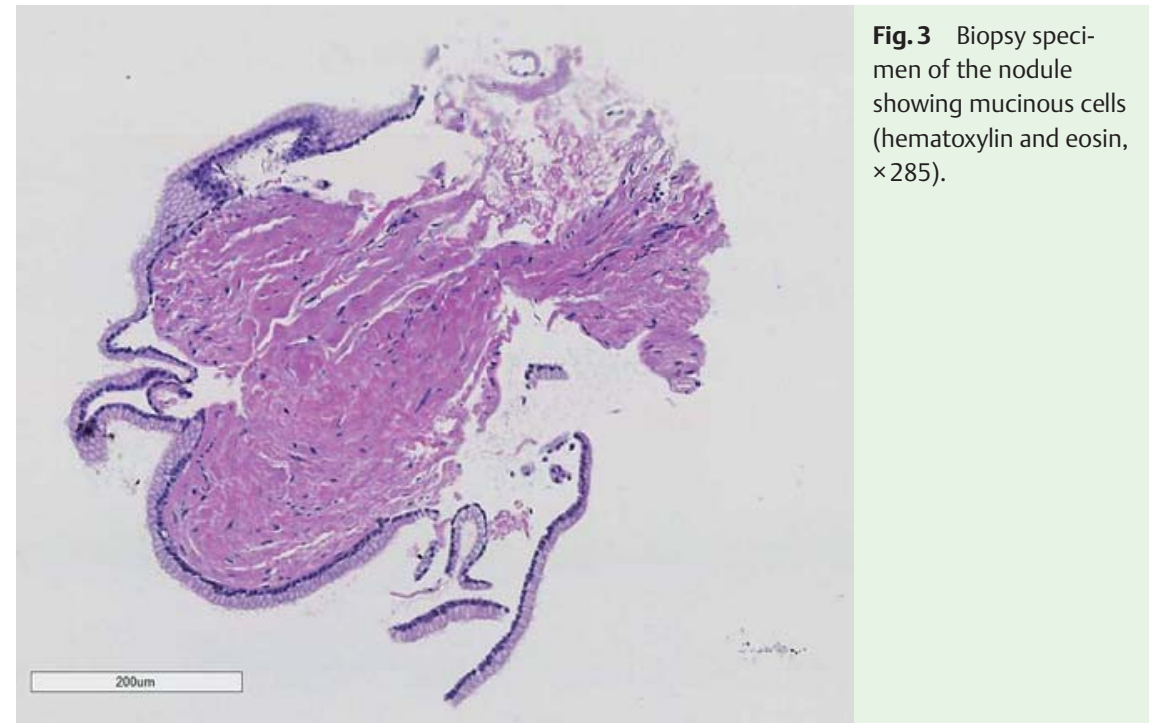

\section{References}

1 Laffan TA, Horton KM, Klein AP et al. Prevalence of unsuspected pancreatic cysts on MDCT. Am J Roentgenol 2008; 3: 802 - 807

2 de Jong $K$, Nio CY, Hermans JJ et al. High prevalence of pancreatic cysts detected by screening magnetic resonance imaging examinations. Clin Gastroenterol Hepatol 2010; 9: 806-811

3 Tang S-J, Vilmann AS, Saftoiu A et al. EUS needle identification comparison and evaluation (NICE) study (with videos). Gastrointest Endosc 2016. DOI: 10.1016/j. gie.2016.01.068
4 Barresi L, Tarantino I, Ligresti $D$ et al. A new tissue acquisition technique in pancreatic cystic neoplasm: endoscopic ultrasoundguided through-the-needle forceps biopsy. Endoscopy 2015; 47 (Suppl. 01): E297-298

5 Aparacio RJ, Martínez J, Niveiro M. Direct intracystic biopsy and pancreatic cystoscopy through a 19-gauge needle EUS (with videos). Gastrointest Endosc 2010; 72: 1285 1288

6 Samarasena BJ, Nakai Y, Shinoura S. EUSguided through-the-needle forceps biopsy: a novel tissue acquisition technique. Gastrointest Endosc 2015; 81: 225-226

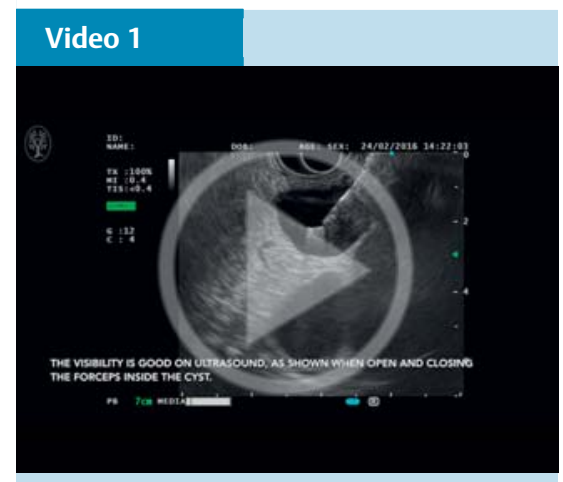

Endoscopic ultrasound-guided biopsy of pancreatic cyst wall using a through-the-needle micro forceps (Moray, US Endoscopy, Ohio, USA).

\section{Bibliography}

DoI http://dx.doi.org/

10.1055/s-0042-105437

Endoscopy 2016; 48: E125-E126

(c) Georg Thieme Verlag KG

Stuttgart · New York

ISSN 0013-726X

\section{Corresponding author}

\section{Khanh Do-Cong Pham, MD}

Section of Gastroenterology

Department of Medicine

Haukeland University Hospital

Jonas Lies vei 65

5051 Bergen

Norway

Fax: +47-55955000

pham@helse-bergen.no 